\title{
Educação contextualizada
}

e seus impactos na melhoria

da qualidade do ensino e

enfrentamento à pobreza no

Território do Sisal Baiano

Contextualized education and its impacts on improving

the quality of education and coping with poverty in the

Territory of Sisal Baiano

Ana Paula Mendes Duarte ${ }^{1}$

Jurandir de Almeida Araújo²

\section{RESUMO}

O presente trabalho versa sobre os processos de educação contextualizada e seus impactos diretos frente à pobreza no Território do Sisal,

1 Graduada em Letras Vernáculas pela Universidade Estadual de Feira de Santana (UEFS). Especialista em Educação, Pobreza e Desigualdade Social, pela Universidade Federal da Bahia (UFBA). Orientadora Educacional em Feira de Santana- BA. Membro do Grupo de Pesquisa em Política e Avaliação Educacional (GEPALE- BA). E-mail: aninha.fsa19@gmail.com

2 Doutorando em Educação pela Universidade Federal da Bahia (UFBA). Mestre em Educação e Contemporaneidade pela Universidade do Estado da Bahia (UNEB). Graduado em Pedagogia (UNEB). Membro do Grupo de Pesquisa Políticas e Gestão da Educação e da Associação Brasileira de Pesquisadores(as) pela Justiça Social (Abrapps). Professor do curso de Pedagogia da Fundação Visconde de Cairu (FVC) e do curso de Pedagogia EAD/UNEB. E-mail: juran-araujo@hotmail.com 
na Bahia, a partir das contribuições e experiências das organizações sociais para a diminuição da pobreza, da garantia dos direitos de crianças e adolescentes, bem como o desenvolvimento local sustentável. Dessa forma, busca-se analisar como o trabalho do Movimento de Organização Comunitária (MOC), através da metodologia Conhecer, Analisar e Transformar a realidade do campo (CAT), incidem sobre as mudanças e se desdobram frente ao desenvolvimento local sustentável, assim como a situação de extrema pobreza na zona rural. A metodologia documental foi escolhida para traçar e compor o itinerário da pesquisa. Os resultados mostram que a contribuição do MOC foi salutar na mudança da paisagem socioeconômica e cultural de muitas pessoas, em particular de muitas crianças e adolescentes que vivem na zona rural, no Território do Sisal.

Palavras-chave: Educação Contextualizada. Território do Sisal. Pobreza. Desigualdade. Desenvolvimento Local.

\section{ABSTRACT}

This paper deals with contextualized education processes and their direct impacts on poverty in the Territory of Sisal, Bahia, based on the contributions and experiences of social organizations to reduce poverty, guarantee the rights of children and adolescents, as well as sustainable local development. In this way, it is sought to analyze how the work of the Community Organization Movement (MOC), through the methodology Know, Analyze and Transform the reality of the field (CAT), focus on the changes and unfold in front of sustainable local development, as well as the situation of extreme poverty in the rural area. The documentary methodology was chosen to trace and compose the research itinerary. The results show that the contribution of MOC has been salutary in changing the socioeconomic and cultural landscape of many people, particularly many children and adolescents living in rural areas in the Sisal Territory.

Keywords: Contextualized Education. Territory of Sisal. Poverty. Inequality. Local Development. 


\section{INTRODUÇÃO}

Um dos maiores problemas da educação contemporânea é a evasão escolar e uma escola que não dialoga com a realidade dos/as educandos/as, que enxerga a pobreza como uma condição e utiliza a meritocracia como ferramenta para dialogar com os/as alunos/as na educação pública, sem refletir os processos históricos e estruturais que a envolvem, reproduzem e mantém. Diante esse contexto, pensando a realidade dos partícipes do processo educacional no Território do Sisal, no semiárido baiano, o Movimento de Organização Comunitária (MOC) desenvolveu uma proposta metodológica baseada na ação-reflexão-ação da Educação Popular, concretizada na proposta Conhecer, Analisar e Transformar a realidade do campo (CAT), com a qual os municípios garantem a efetivação da Educação Contextualizada.

A proposta desenvolvida ganha destaque quanto à melhoria do aprendizado dos/as educandos/as das escolas do campo, bem como organização comunitária e maior participação das famílias nas escolas. Assim, passa a dialogar com a realidade das comunidades, problematizando-a e melhorando a qualidade de vida não com o fomento de políticas educacionais que coadunem com o combate à seca, mas com uma educação descolonizadora e emancipatória, na qual as políticas estejam voltadas para a convivência com o semiárido.

Diante do exposto, este estudo objetiva analisar a experiência exitosa que acontece no semiárido baiano, através da metodologia de educação popular do campo, a qual incide sobre as mudanças e se desdobra frente ao desenvolvimento local sustentável, assim como a situação de extrema pobreza no território do sisal, no semiárido baiano. Pois, percebe-se que nos municípios de atuação do MOC, as crianças estão acessando na escola a construção de conhecimentos pela via da educação libertadora como concepção que as empoderam e que cumpre sua função social de transformação da comunidade. Uma Educação Contextualizada que relaciona os conteúdos curriculares com a realidade local.

Percebe-se também que nesse processo, o cotidiano da comunidade é conhecimento que é conhecido, analisado e transformado para 
além do espaço escolar, envolvendo a comunidade, tendo as dimensões da agroecologia, alimentação saudável, segurança alimentar e nutricional, água, território, desenvolvimento local sustentável. Tudo isso relacionado de modo interdisciplinar com a geografia, matemática, ciências, linguagens (língua portuguesa, artes e outras). E assim, seguindo o itinerário pedagógico que torna uma cisterna e uma horta escolar em ferramenta pedagógica para a prática dos alunos e alunas, numa ação que envolve transdisciplinaridade e interdisciplinaridade.

Metodologicamente ancorado na pesquisa de abordagem documental, o estudo tem como um dos principais insumos a análise de documentos e relatórios institucionais ao longo dos últimos anos (1994 a 2015). Neste sentido, os métodos de elaboração deste trabaIho seguiram inicialmente o levantamento dos documentos e relatórios encontrados na Instituição, bem como documentos de entidades parcerias, a saber, do Conselho de Desenvolvimento Sustentável (CODES Sisal), para coletar dados que se relacionavam com o tema deste trabalho e que tivessem como local de ação o Território do Sisal e a incidência do MOC relatada nestes documentos e em outros materiais publicados pela própria entidade. A opção por essa por essa abordagem se deu pois, a pesquisa documental caracteriza-se pela análise de materiais que não tiveram um estudo aprofundado, ou que ainda estão em estado bruto, necessitando a seleção e delimitação das informações a fim de tratar e interpretar, buscando extrair insumos que contribuam para a comunidade científica e disseminar tais materiais (SILVA; GRIGOLO, 2002).

E parte-se dos pressupostos teóricos de Rosa e Caetano (2008), a concepção ideológica da educação rural não estabelece nenhum tipo de relação com o desenvolvimento local, mas em sua estruturação sempre predominou visão de educação limitada, assistencialista e que via os sujeitos do campo como povos subordinados, subalternos ao urbano, atrasado, sem tecnologia e até mesmo sem cultura. $E$ isso não favorecia a construção de uma educação fortalecedora de identidades, bem como trazia uma visão antagônica entre campo e cidade. Nesta perspectiva, a defesa de uma educação do e no campo. 


\section{POR UMA EDUCAÇÃO DO E NO CAMPO}

A verdade é que quando a visão de desenvolvimento rural começa a ser delineada a partir do desenvolvimento territorial local, a educação rural, que já sofria durante anos críticas e ressalvas dos Movimentos Sociais do Campo, que não viam representatividade na Educação Rural, torna-se obsoleta. Assim, na busca de legitimar uma educação emancipatória para os povos do campo, a Conferência Nacional de Educação do Campo (1998), na qual o modelo de educação rural é rejeitando e os Movimentos compostos por diversas entidades ligadas ao campo constroem a nomenclatura "Educação do Campo", pela permanência e pelo direito à uma educação "do" campo e "no" campo (CARNEIRO, 2012).

A concepção de Educação do Campo, no sentido de representar os trabalhadores e trabalhadoras que vivem no Campo, é legítima e demandada pelos Movimentos Sociais do campo, que diferentemente da Educação Rural, foi bandeira de luta destes movimentos e por eles pensada. Desse modo, a Educação do Campo em sua concepção ideológica visa à inclusão dos valores, cultura e modos de vida dos povos do campo como conhecimento necessário a ser integrado ao currículo escolar e com práticas pedagógicas que coadunem com a contextualização da realidade. Uma educação,

[...] voltada ao interesse do campo, voltada ao interesse e ao desenvolvimento sociocultural e econômico dos povos que habitam e trabalham no campo, atendendo às suas diferenças históricas e culturais para que vivam com dignidade e para que, organizados, resistam contra a exploração e a expropriação, ou seja, este do campo tem o sentido do pluralismo das ideias e das concepções pedagógicas: diz respeito à identidade dos grupos formadores da sociedade brasileira (conforme os artigos 206 e 216 da nossa Constituição) (KOLLING; NERY; MOLINA, 1999, p. 29).

A partir desse marco histórico, os movimentos passam a atuar em busca de políticas públicas de educação do campo e desenvolvimen- 
to local com mais força e balizados por uma concepção criada pelos próprios movimentos. Deste modo, a educação rompe com uma visão tradicional e dicotômica, para propostas e práticas pedagógicas colaborativas, territoriais, estabelecendo uma relação de diálogo com o Estado e abordando as diferenças entre campo e cidade de um ponto de vista dialético e complementar entre ambos os espaços.

Contudo, cabe destacar que essas iniciativas não vieram de experiências formais, das gestões municipais ou estaduais de educação, mas de organizações da sociedade civil como as Organizações Não Governamentais (ONGs), Organizações Comunitárias, Sindicatos e Coletivos (PEREIRA, 2013). Sendo assim, a Educação Rural e a Educação do Campo passam a ser concepções antagônicas. A primeira, financiada e respaldada pelo Agronegócio e a segunda, fundamentada nas lutas dos Movimentos Sociais do Campo em favor da Agricultura Familiar (LIMA; SILVA, 2014). Cabe destacar também que durante muito tempo a educação rural existiu de forma muito precária e veio mais como favor do que como direito. Além de não levar em consideração o contexto da população do campo, não se relacionava com a vida e os saberes das pessoas.

Conforme Arroyo, Caldart e Molina (2004), a história da educação rural permite constatar que a escola rural sempre foi tratada como retrocesso e nunca teve investimentos, sempre ficava com as sobras das escolas urbanas, havendo assim uma negação do direito à educação de qualidade para o povo do campo. A lógica da elite agrária não permitia que a educação rural e o desenvolvimento caminhassem juntos, portanto a educação precária era, segundo os referidos autores, uma intenção ideológica de aparelhamento.

Como contraponto a lógica evolucionista e de invasão do capital ao campo, a educação do campo possui uma perspectiva pedagógica que convive e favorece a heterogeneidade. De acordo com Pereira (2013, p. 24) "a educação não pode se limitar a constituir um tipo de estoque básico de conhecimentos". Em que a educação do campo não é "beneficiada" por pacotes, mas onde as pessoas do território ou comunidade conhecem e problematizam a sua realidade, o seu entorno, ou seja, pensam as alternativas e as potencialidades ao seu 
redor e tem a escola como mediadora desse processo de construção de conhecimento local e de relação com os conhecimentos gerais e correspondentes. Neste sentido, o autor destaca que o discurso contra hegemônico "não se trata de uma diferenciação discriminadora, do tipo 'escolas para pobres': trata-se de uma educação mais emancipadora na medida em que se assegura à nova geração os instrumentos de intervenção sobre a realidade que é a sua" (PEREIRA, 2013, p. 24).

Para Caldart (2002) das características fundamentais do movimento por uma educação do campo é a luta pela educação na perspectiva da Política Pública, enquanto direito inegociável contextualizada com a sua realidade e no local onde vive, pensada para e com os sujeitos do campo, pensando o desenvolvimento local. Nessa direção, o Art. $2^{\circ}$, Parágrafo único, das Diretrizes Operacionais para Educação Básica do Campo, diz que:

Art. $2^{\circ}$ - A educação do campo é uma concepção política pedagógica voltada para dinamizar a ligação dos seres humanos com a produção das condições de existência social, na relação com a terra e o meio ambiente, incorporando os povos e o espaço da floresta, da pecuária, das minas, da agricultura, os pesqueiros, caiçaras, ribeirinhos e extrativistas (BRASIL, 2002).

Em sua concepção e princípios a educação do campo se estrutura a partir da valorização da identidade e tendo como insumos elementos da própria realidade de vida dos sujeitos. O Art. $2^{\circ}$ traz ainda a constituição dos povos que vivem no semiárido, com seu modo de vida, seus saberes e fazeres como conhecimento legítimo e constituído sobre o qual os filhos e filhas dos/as agricultores/as familiares tem como direito o acesso nos espaços educacionais formais e não formais. De uma perspectiva universalista da Educação Rural à contextualização dos saberes em Educação do Campo, o local é entendido como o começo, o ponto de partida para construção de conhecimentos, do local para o global, do micro para o macro. De acordo com Reis (2011, p. 101):

Ter como lócus investigativo uma escola do campo busca-se romper com o lugar comum que a ciência moderna tem dado 
aos saberes distintos de comunidades específicas e principalmente aos saberes cotidianos que foram desprezados por um cientificismo cético, que deixou de considerar os processos subjetivos que aí são construídos, que dão sentido a vida e a práxis cotidiana dos sujeitos desse fazer, e que, portanto, precisam ser trabalhados pela escola, uma vez que o processo educativo passa a funcionar como espaço de socialização e construção de sentido na vida dos que estão envolvidos nesta atividade.

Nesta direção, em 2002, a Rede de Educação do Semiárido Brasileiro (RESAB) é oficializada e mobiliza junto com suas entidades e organizações em defesa da educação do campo debates nas esferas estaduais e nacional que culminaram na Oficina sobre as Diretrizes Operacionais por uma Educação Básica para as escolas do Campo. Publicada em abril de 2002, é considerada o maior marco legal da Educação do Campo do país, sendo um documento legítimo e elaborado de forma coletiva, por meio da qual a Educação do Campo é documentada em seus princípios e concepções e onde não há mais lugar para a extinta Educação Rural.

Nesse processo de luta e legitimação da Educação do Campo, o MOC participou ativamente, e foi nessa caminhada que o CAT foi se delineando e aderindo a concepção de Educação do e no Campo, como parte intrínseca do movimento que a pensou e concretizou em suas experiências. Durante todo esse processo, muitos foram os desafios e descobertas no itinerário pedagógico, um deles é a relação educação e pobreza e tem provocado um grande impacto e feito o diferencial na Região Sisaleira baiana, situada no semiárido baiano geográfica e politicamente. Posto que as tentativas históricas de naturalização da negação de direitos pela via das circunstâncias climáticas e geográficas marcou esse campo.

No decorrer da história do país, a pobreza extrema no Nordeste brasileiro levou muitas famílias a recorrer desde muito cedo à exploração da mão de obra de crianças e adolescentes, o trabalho infantil, para garantir a sobrevivência das famílias. Neste sentido, as influências econômicas e políticas que delinearam uma escolha de negligenciar e relegar o semiárido, atribuindo-lhe um lugar de atraso e de impossibilidades, culpando o clima e as ruralidades por isso, bem como acentuando a oposição e os conflitos dicotômicos entre campo e cidade, 
como se jamais fosse possível entende-los se relacionando no mesmo patamar, estando o campo sempre em lugar aquém e subalterno, assim o Território do Sisal foi forjado.

Uma característica muito forte e importante do Território do Sisal, é que a incidência dos Movimentos Sociais, do Sindicalismo e ativismo de ONGs sempre foi uma forma de resistir ao latifúndio e a concentração de renda na mão da elite. Historicamente, como já sinalizado, está é uma região pioneira no abandono das perspectivas de políticas de combate á seca e várias de suas entidades e organizações passam a integrar a Articulação no Semiárido Brasileiro (ASA) e ajudam na elaboração do documento símbolo dessa ruptura político-filosófica: a Declaração do Semiárido Brasileiro, na qual a demanda e luta é por justiça social a partir das perspectivas das políticas públicas de convivência com o Semiárido (ASA, 1999). Dentre as organizações que compõem o documento e a constituição da ASA está o MOC.

Assim sendo, podemos inferir que essa atmosfera de lutas, articulações entre os Movimentos Sociais e Sociedade Civil Organizada juntamente com a abertura para o diálogo com o Governo que repensou a forma de olhar para o semiárido e para a população da zona rural contribui para o desenvolvimento sustentável no Semiárido e, consequentemente, no Território do Sisal. E, conforme as perspectivas de mudanças no campo das políticas públicas foram sendo concretizadas e aos poucos melhorando a qualidade de vida das famílias do Território (SILVA; CARVALHO, 2015). Neste contexto, o MOC foi uma das entidades mais fomentadoras da organização social no Território do Sisal, por isso mesmo, a história do Território se cruza com a caminhada da instituição, que tem como missão a luta por um Sertão mais justo, história que segue contada na seção seguinte.

\section{MOVIMENTO DE ORGANIZAÇÃO COMUNITÁRIA: UM HISTÓRICO DE LUTA "POR UM SERTÃO JUSTO"}

O Território do Sisal, pode-se afirmar, é um dos destaques nacionais quando o assunto é organização social. O legado de inúmeras 
organizações, sindicatos, cooperativas e associações provocaram mudanças significativas neste espaço na última década. Um lugar cujos índices de trabalho infantil, analfabetismo, subemprego e pobreza eram assustadores, o Território é hoje exemplo de organização e desenvolvimento sustentável.

Assim, diante desse contexto de mudança, compartilha-se do pensamento de Gohn (2005, p. 16) que "a condição de cidadania é construída por meio do cotidiano nos processos de identidade político cultural que as lutas cotidianas geram". Neste sentido, as organizações que compõem o Terceiro Setor da Sociedade Civil Organizada que estiveram à frente mobilizando e encampando lutas e resistências em suas regiões e territórios, até mesmo antes de sua abertura política após o fim da ditadura militar, são historicamente responsáveis pelas tensões que geraram mudanças que culminaram na quebra de paradigmas e retrocessos de políticas assistencialistas.

São responsáveis também pelas reivindicações por políticas públicas de enfrentamento as desigualdades sociais, pelas concepções, princípios e filosofias educacionais na perspectiva libertadora e popular. No caso das políticas públicas para o campo, forjada nas lutas dos movimentos sociais do campo, por sua capacidade de organização popular. E foi neste contexto de reivindicações, mobilizações e organizações populares, o MOC, organização não governamental, com sede situada em Feira de Santana, Bahia, foi fundado em 1967, em pleno período de ditadura militar (instituída pelo golpe em 1964), pelo então padre Albertino Carneiro. Advindo da comunidade de Malhador, em Riachão do Jacuípe, o padre sabia como a vida no campo era difícil, sem acesso a cidadania e aos direitos básicos. Assim, contando com o apoio da Igreja Católica, que neste período tinha um forte trabalho com as comunidades de base, cria o MOC que iniciou sua trajetória de incidência tendo como mote a construção da cidadania.

Nesse começo, o MOC atuava nos 30 municípios que estavam na abrangência da Diocese de Feira de Santana, com uma reduzida equipe de trabalho e pouco apoio financeiro. Com o tempo foi ganhando força, e outras organizações e instituições foram se aproximando, como a Universidade Católica, a Universidade Federal da Bahia 
(UFBA) e a Universidade Estadual de Feira de Santana (UEFS), que disponibilizavam estudantes estagiários para contribuir tanto nos processos formativos como assistenciais (DUARTE et al, 2015).

Quando a Ditadura Militar endureceu ainda mais, a partir do Ato Institucional $\mathrm{N}^{\circ} 05$ (Al 5) ${ }^{3}$, o MOC contava com o apoio da Igreja Católica, mas mesmo assim foi chamado a prestar esclarecimentos pelos militares. Começam a surgir os primeiros conflitos com a própria Igreja, inclusive porque o MOC era simpático as ideias da Teologia da Libertação (DUARTE et.al, 2015). Assim, no segundo trecho da entrevista, o padre Albertino nos conta que:

Fui inquirido pela Segurança Nacional e me perguntaram: por que você está fazendo um trabalho clandestino? Expliquei que era padre e meu trabalho era realizado com a Diocese. Eles me disseram que se eu não registrasse iriam considerar o movimento como comunista, MOC- Movimento Operário Comunista. Foi aí que eu disse: Não, o senhor está mal informado, não é um trabalho clandestino não, nós não temos medo de dizer o que somos e o que fazemos (PADRE ALBERTINO, 2015, apud DUARTE et al, 2015, p. 10).

Após este episódio, a filiação do MOC à Diocese de Feira de Santana não resistiu muito tempo. A própria Igreja tecia críticas ao padre Albertino e nos bastidores muitos o viam como um comunista. Então, em 1970 o MOC é registrado como pessoa jurídica e entidade autônoma, elegendo diretoria, elaborando seu estatuto e se categorizando enquanto organização não governamental, entidade filantrópica (DUARTE et.al, 2015) e segue suas ações, chegando à década de 1980.

A década de 1980 é marcada pela ação do MOC na mobilização para o acesso aos direitos. Associações começam a ser criadas e o MOC passa a contribuir na assessoria e fomento ao associativismo, sindicalismo. Enfim, passa a traçar programas para linhas de ações.

3 O Ato Institucional $N^{\circ} 05$ foi decretado no final de 1968 marcou o endurecimento do regime ditatorial por qual passou o Brasil. O AI 5 decretou oficialmente o estado de exceção, pelo qual os governantes tiveram plenos poderes de punição a quem se opusesse ao Regime Militar, consolidando a intolerância do governo a toda e qualquer crítica e oposição. 
É nessa mesma década que se inicia o trabalho com educação de jovens e adultos (DUARTE et. al, 2015).

Conforme os estudos de Silva e Carvalho (2015), a atuação do MOC se expande gradativamente e passa a integrar em suas linhas de ações a formação de lideranças sociais, gestão de políticas públicas. Passa também a dar maior ênfase na concepção da conivência com o Semiárido, na dimensão de gênero, geração, raça e etnia, bem como a comunicação comunitária e a Educação Popular, assim como passa a ter atuação estratégica na incidência política de redes e fóruns de educação e suas temáticas de expertise. De acordo com os referidos autores, a área de abrangência do $\mathrm{MOC}$ acontece em três territórios prioritários que concentram maior número de projetos, a saber: o Território Portal do Sertão, o Território do Sisal e o Território da Bacia do Jacuípe.

O MOC participou desde o processo de identificação e demandas e lutas pela implantação de instituições federal, estadual, cursos de Educação Profissional, que hoje ocupam os espaços educacionais no Território, fortalecendo-o, tais como:

- Implantação da Escola de Ciências em Serrinha;

- Chegada do IF Baiano no Território - Campus Serrinha. Cursos em 2015: Técnico em Agroecologia Integrado; subsequente em Agropecuária em regime de alternância.

- Implantação dos Centros Territoriais de Educação Profissional (CETEPs) Semiárido em São Domingos e Paulo Freire em Santa Luz.

- 03 Escolas Famílias Agrícolas (EFAs) desenvolvendo a Pedagogia da Alternância nos municípios de Itiúba (69 alunos), Valente (102 alunos) e Monte Santo (380);

- Ampliação e implantação de cursos superiores, a exemplo da consolidação do Curso Comunicação Social da UNEB - Conceição do Coité;

- Produção de materiais didáticos e pedagógicos contextualizados com o Semiárido, produzidos no Território; 
- Pesquisas e produções científicas - Monografias e Dissertações sobre os projetos educacionais no Território;

- Formação continuada e processual, com princípios, concepção e metodologia de Educação do Campo de aproximadamente 60 coordenações municipais e mais de 600 Professores/as de escolas do campo do Território, desenvolvido pelo MOC em parcerias com a UEFS, as Prefeituras Municipais, Movimentos Sociais e Sindicais do campo;

- Reconhecimento de experiências de Educação do Território em âmbito internacional;

- Surgimento de Grupos de Culturais, como teatro, poesias, danças, pintura, música e literatura a partir do incentivo na Educação Contextualizada;

- A alimentação escolar com origem na agricultura familiar a partir dos programas Programa Nacional de Alimentação Escolar (PNAE) e Programa de Aquisição de Alimentos (PAA).

Cabe destacar que, em se tratando de Paulo Freire, um dos marcos na história da educação brasileira, foi o Movimento de Educação Popular, no qual o educador elaborou um método de educação progressista, libertadora e que foi fomentado pelas Organizações de Base da Igreja Católica, Pastorais e Círculos de Cultura, em defesa da educação pública gratuita, laica e contextualizada. É neste ambiente que surge a Ação-Reflexão-Ação, proposta criada pelo próprio Paulo Freire, com base em seus estudos na Educação Popular, num período difícil em que se fortalece a luta pelo acesso à terra e contra o Agronegócio, encampado pelas Ligas Camponesas (BAPTISTA, 2006).

\section{EDUCAÇÃO CONTEXTUALIZADA: CONHECER, ANALISAR E TRANSFORMAR A REALIDADE DO CAMPO}

Nesta perspectiva, o Projeto Conhecer, Analisar e Transformar a realidade do campo (CAT) surgiu em 1994 de uma parceria entre 
- MOC e a Universidade Estadual de Feira de Santana (UEFS), na Bahia, e Serviço de Tecnologia Alternativa (SERTA), de Pernambuco. E tem como foco a formação continuada de professores e professoras das escolas do campo, trazendo uma metodologia de trabalho contextualizada com a vida no campo, analisando o entorno das comunidades e buscando transformar este espaço através do desenvolvimento sustentável.

Cabe ressaltar que na década de 1990 a proposta de educação ainda era pautada como "educação rural", tendo como base a educação tradicional e descontextualizada para a realidade das populações que vivem no campo, tendo como objetivo apenas o processo de alfabetização pela via da decodificação. Assim, o Projeto CAT iniciou suas proposições pela mudança do currículo oficial dos municípios, que, conforme caracterização do IBGE (1999) são considerados rurais pelas atividades econômicas, culturais e pela vida social ser influenciada pelo campo, tendo inclusive maior parte da população vivendo na zona rural e que, portanto, necessita de uma educação que aborde a vida do campo, seus conhecimentos e a convivência com o Semiárido (SOUZA, 2004).

Com base no CAT e nas ações da Jornada Ampliada do PETI, em 1999 o MOC cria em parceria com o Fundo das Nações Unidas para a Infância (UNICEF) o Projeto Baú de Leitura, como estratégia para o incentivo à leitura lúdica e contextualizada nas escolas do campo para diminuição da evasão escolar, analfabetismo e na luta contra o trabaIho infantil na região, que no campo é três vezes maior que na região urbana (CARNEIRO, 2011).

Cabe ressaltar que o MOC, em seu histórico, sempre foi caracterizado pela capacidade de mobilização e organização de novas entidades e grupos sociais organizados. Um dos espaços de discussão e articulação política se constituiu o Conselho de Desenvolvimento Rural Sustentável do Território do Sisal, o CODES Sisal, a partir da política de desenvolvimento territorial do Governo Federal, é criado envolvendo poder público, universidades e sociedade civil organizada em 2004. Nesse mesmo período, o CODES constrói vários grupos de trabalhos temáticos para construir o primeiro Plano Territorial de Desenvolvi- 
mento Sustentável do Sisal (PTDSS). O Programa de Educação do Campo Contextualizada (PECONTE) então integra o GT de Educação, no qual participa e contribui com discussões e pautas que demandam melhor qualidade da educação do Território (CARNEIRO, 2012).

Em 2010, o PTDSS é compilado e publicado, traçando um desenho da realidade do Território, além de demandas e metas para serem alcançadas e articuladas enquanto políticas e programas para os próximos anos. Para a elaboração das propostas de educação, o MOC contribuiu participando do ciclo de 08 oficinas para construção, inserindo no debate a necessidade de o Território definir a proposta de Educação do Campo contextualizada como filosofia de educação e pensar todas as ações nessa perspectiva, coadunando com o desenvolvimento local sustentável. Além disso, conforme assevera o Relatório do MOC: Territórios em Movimentos, de 2015,

O entendimento é que não era possível construir um desenvolvimento sustentável sem investir em educação. A Pobreza e o analfabetismo andam juntos. Dessa forma, iniciou com a construção de um diagnóstico e a partir deste se construiu o Plano, com objetivos e metas para superar o atraso educacional, as dificuldades encontradas e garantir Educação do Campo de qualidade. (MOC, 2015, p. 01)

A partir desse entendimento, o PTDSS apresentou demandas e dados que chamavam o Território para pensar a educação do campo nos municípios, bem como sua concepção e o diálogo com o princípio do desenvolvimento rural sustentável, elencando as problemáticas e demandas urgentes no período em que o Plano foi sendo construído. Tais como: analfabetismo rural maior que urbano; $87 \%$ alimentação escolar industrializada e tratada ainda como "merenda"; inexistência de metodologia específica em Educação do Campo - apenas 07 municípios desenvolviam a experiência do CAT; poucos cursos e campus universitários; inexistência de projetos de incentivo à leitura; inexistência de institutos e cursos profissionalizantes; Educação do Campo existia enquanto projeto/experiência e não enquanto política pública educacional (MOC, 2015). 
A partir da elaboração e publicação do PTDSS, o CAT e o Baú de Leitura passam a ser vistos não mais como projetos e o MOC em mudança de estratégia amplia suas ações não apenas para o campo formativo, mas passa a montar estratégias para que as propostas e experiências metodológicas tivessem incidência enquanto política pública. Neste contexto, apresenta-se duas imagens, ambas possuem perspectivas de vida muito diferentes, ainda que pertençam a mesma região e ilustram bastante as discussões trazidas no decorrer deste estudo.

Operação tapa-buraco, o retorno: A exploração do trabalho infantil e a degradação da infância no semiárido baiano

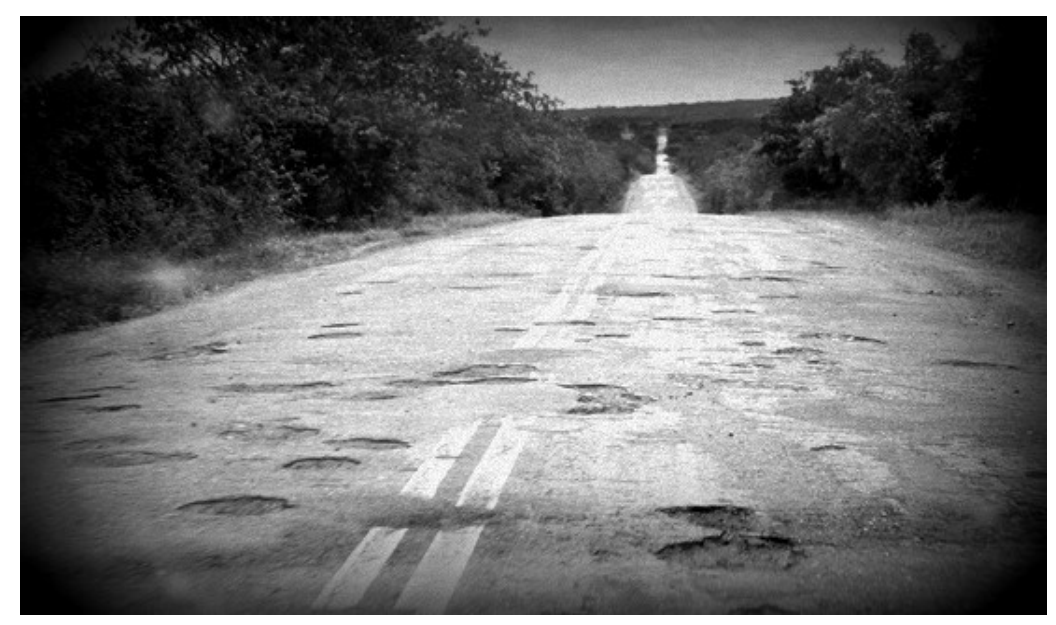

Fonte: Acervo da autora.

Cores, sabores, saberes e fazeres da resistência: a educação contextualizada valorizando a vida, a identidade e transformando vidas nas escolas do campo

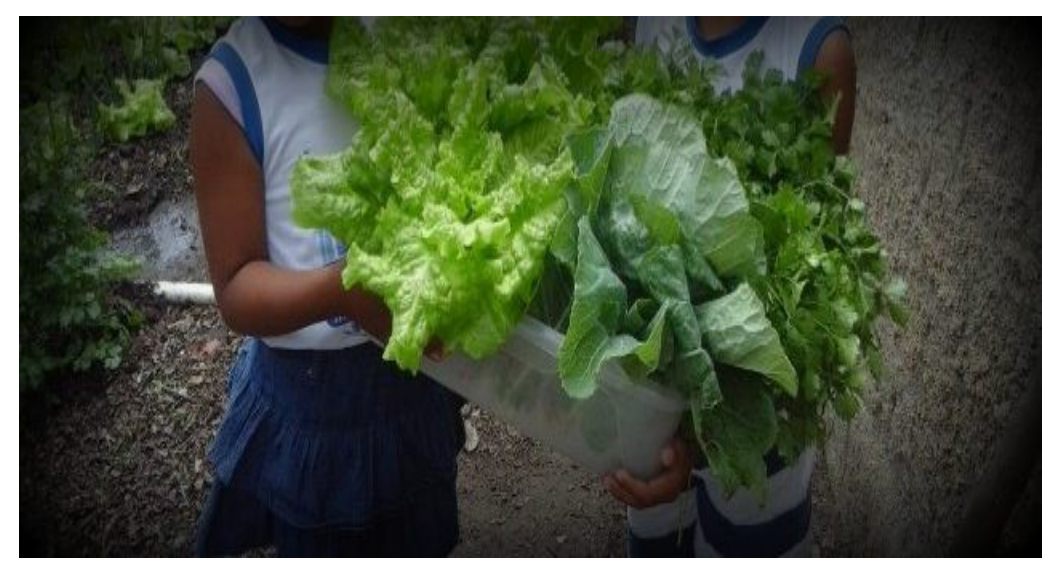

Fonte: Acervo da autora. 
A primeira fotografia intitulada de "Operação tapa-buraco, o retorno: A exploração do trabalho infantil e a degradação da infância no semiárido baiano", representa uma realidade que se acreditava extinta em boa parte das rodovias da Bahia durante anos, mas agora retornam com tristeza e causa indignação a quem passa. Ressaltando que o recurso de usar o efeito preto e branco foi a fim de trazer a emoção da tristeza e da ideia de uma memória que se quer esquecer, porém retorna agora como uma válvula de escape de muitas famílias que sobrevivem apenas com o Bolsa Família e outras que nem isso tem.

Relacionando a fotografia com os conteúdos postulados sobre o conceito de pobreza multifacetado e na qual se faz a necessidade de recortes interseccionais, no caso dessa fotografia, ela foi tirada num espaço rural, um dos locais dos "povos sem Estado", uma vez que é um território negligenciado, com ausência durante séculos de políticas públicas básicas e essenciais que garantissem o exercício da cidadania e o rompimento com o ciclo de pobreza. Numa região que, como já discutido, durante anos protagonizou os maiores índices de trabalho infantil do país, o que foi enfrentado através da implementação de algumas políticas pública de enfrentamento a essa prática, porém com a crise econômica que se agravou em 2016 no país, relembrando o que disse o cientista político Streeten (1995, p. 30), "a renda dos pobres tende a variar consideravelmente de ano em ano e de estação a estação, no contexto do ano, dependendo do tempo e de outros acidentes".

Esse ciclo parece se reproduzir (em menores proporções ainda) de maneiras diferentes, porém tão preocupantes quanto as anteriores e necessita de uma leitura, abordagem e intervenção plural e interseccional, uma vez que percebemos que a pobreza não possui um conceito absoluto ou único, mas é multifacetada. A maioria dos programas, políticas e ações que visam lidar com as situações de pobreza terminam por não conseguir fazer tais recortes.

Conforme postulam Destremau e Salama (1999, p. 18) "por vezes, finos conhecedores da pobreza no papel são incapazes de compreendê-la na vida cotidiana e, chamados à responsabilidade, seja nas organizações internacionais ou nos governos, preconizam políticas no mínimo inadequadas". Neste contexto, os buracos e as crianças estão 
ali para nos dizer alguma coisa: os programas e políticas que vieram para as famílias em situação de vulnerabilidade foram insuficientes, não foram capazes de romper com os problemas estruturais, muito embora fossem importantes e emergentes.

A segunda fotografia, intitulada de "Cores, sabores, saberes e fazeres da resistência: a educação contextualizada valorizando a vida, a identidade e transformando vidas nas escolas do campo", traz uma perspectiva positiva e mais cidadã das crianças e adolescentes em situação de pobreza. $\mathrm{Na}$ foto as crianças estão na escola construindo conhecimentos, tendo a educação libertadora como concepção que as empodera e que cumpre sua função social de transformação da comunidade. Educação contextualizada que relaciona os conteúdos curriculares com a realidade local, na verdade, o cotidiano da comunidade é conhecimento que é conhecido, analisado e transformado para além do espaço escolar, envolvendo a comunidade, tendo as dimensões da agroecologia, alimentação saudável, segurança alimentar e nutricional, água, território, desenvolvimento local sustentável. Tudo isso relacionado de modo interdisciplinar com os diferentes componentes do currículo, assim seguindo o itinerário pedagógico que torna uma cisterna e uma horta escolar em ferramenta pedagógica para a prática dos(as) alunos(as). Como ponderam Wilkinson e Pickett (2010, p. 115):

[...] aprendemos melhor em ambientes estimulantes, quando somos confiantes de ter sucesso", uma vez que, [...] quando nos sentimos felizes ou confiantes, nossos cérebros se beneficiam da liberação de dopamina, uma substância gratificante, que ajuda também a memória, a atenção e a solução de problemas". Ademais, a liberação de serotonina [...] melhora o ânimo, e de adrenalina, que nos ajuda a alcançar performances ótimas"; por outro lado, [...] quando nos sentimos ameaçados, desamparados e estressados, nossos corpos são afetados pela liberação do hormônio cortisol, que inibe nossa capacidade de pensar e nossa memória.

Essa é a perspectiva de educação contra hegemônica que empodera, rompe com os processos patriarcais, de negação de direitos 
e que aproxime as famílias da escola, uma educação que faça sentido nas e para a vida das crianças e adolescentes, que oportunize, que traga perspectivas de autonomia para as famílias, afastando assim o fantasma da fome, da insegurança alimentar, do campo esvaziado e do trabalho infantil.

Diante do exposto, com base nas análises realizadas tendo como mote as ações do MOC no Território do Sisal, principalmente a atuação em educação contextualizada através da metodologia CAT, foi possível perceber alguns pontos em destaque. Mas antes mesmos de apresenta-los, vale a pena retomar os dados existentes no Diagnóstico do PTDSS (2004), que diagnosticou as seguintes situações: Analfabetismo rural maior que urbano, 87\%; alimentação escolar industrializada; Inexistência de metodologia específica em Educação do Campo apenas 07 municípios desenvolviam uma experiência; Poucos cursos e campus universitários; Inexistência de projetos de incentivo à leitura; Inexistência de institutos e cursos profissionalizantes; Educação do Campo existia enquanto projeto/experiência e não enquanto política.

Uma realidade que mudou pouco de 2004 até os dias de hoje. Contudo, neste contexto, dos pontos mais relevantes na análise dos relatórios e documentos institucionais analisados, destaca-se a incidência da instituição em Redes, Fóruns, Conselhos e outros espaços de demandas, construção e deliberação de políticas públicas (educacionais, de gênero, agricultura familiar e economia solidária) em nível nacional, estadual e territorial, demonstrando sua ampla capacidade de articulação. Um caráter interessante nos materiais que foram analisados é que ainda que existam números e dados, a preocupação com os resultados é mais qualitativa do que quantitativa.

Além desse ponto mais contundente, outros aspectos também foram constatados a partir dos avanços na Educação do Território do Sisal nos últimos anos a partir dos relatos documentais do MOC, como a considerável redução do analfabetismo rural; a implantação de metodologia de Educação do Campo Contextualizada em 16 municípios e a firme parceria entre o MOC e a UEFS, que juntas estabelecem boas relações com as Prefeituras Municipais, Sindicatos Rurais e ajudam a compor e desenvolver o CODES Sisal. 
De acordo com Caldart (2004), a educação só é universalizada quando se torna um sistema e para isso, precisa ser público, pois assim é capaz de gerar a transformação social e a emancipação dos sujeitos sociais. E foi entre tentativas e lutas que 11 (onze) municípios do Território do Sisal tiveram aprovadas suas próprias Leis Municipais de Educação do Campo Contextualizada e a concretização da educação do campo enquanto política pública municipal. Assim, as propostas metodológicas desenvolvidas pelo MOC enquanto ONG em parceria com a UEFS e Prefeituras Municipais, contribuíram para que se efetivassem políticas públicas na maioria dos municípios do Território do Sisal, que fortalecem a educação da região e torna-se referência nacional e também internacional, como é possível observar nos relatórios da instituição. Tais iniciativas estimularam outras ideias e fomentos educativos, como também novas parcerias interseccionais, intersetoriais e com outras organizações da sociedade civil e poder público (SILVA, 2015, p. 15).

Segundo os dados das somas dos relatórios anuais do MOC (2010-2016) aproximadamente 32 mil crianças e adolescentes do Território do Sisal tem acesso à Educação do Campo Contextualizada através das ações do MOC, a partir da metodologia CAT e Baú de Leitura. Este último tem um número considerável de 540 Baús de Leitura circulando nas escolas do campo e da cidade do Território. Contudo, ainda com todos os avanços e movimentos impulsionados e as Secretaras de Educação avaliarem que o CAT é uma ferramenta fundamental para a valorização dos saberes que dialogam com a vida nas comunidades rurais, bem como melhora a autoestima, envolve as famílias nas escolas, oportuniza formação continuada de professores/as, é preciso que os municípios compreendam e decidam relacionar tal metodologia em consenso com o Currículo, o Sistema de Ensino e Plano Municipal de Educação, de forma que se fortaleça e seja a escolha político, social e pedagógica dos municípios e também em nível de Território (SILVA, 2015).

Além das implementações de políticas públicas e conquistas que mudaram a paisagem social, educacional e econômica do Território do Sisal, outras conquistas válidas e que também contribuíram e con- 
tribuem para o desenvolvimento e empoderamento da região sisaleira, estão a chegada de programas e projetos que contribuíram para a disseminação da educação contextualizada e juntamente como os processos educativos do MOC, potencializaram a educação do território, como a Educação de Jovens e Adultos (EJA), Movimento de Alfabetização de Jovens e Adultos (MOVA), Todos pela Alfabetização (TOPA), PROEJA Campo, Mais Educação, Saberes da Terra, Escola da Terra, cursos do PRONERA, etc. (DUARTE, et al., 2015).

A metodologia CAT, pondera Carneiro (2012), necessita ser visto e incentivado como política pública e não mais como um projeto ou programa piloto em escolas específicas. Precisa ser universalizado, ter orçamento específico que Ihe garanta autonomia, contribuindo assim para o fortalecimento das organizações comunitárias sociais nas comunidades e municípios, tendo a escola como espaço de integração e de transformação, assim como concretizar o plano de desenvolvimento dos municípios e do Território.

\section{CONSIDERAÇÕES FINAIS}

A partir do desenvolvimento rural sustentável como uma prática econômica e social possível, sobretudo com o desenvolvimento de uma educação que foi construída para a região, contextualizada com um itinerário pedagógico que não só traz a realidade local, mas problematiza-a e provoca para uma intervenção, a ação do MOC no Território do Sisal se estendeu à Assistência Técnica Rural, produção de alimentos e agroecologia, acesso ao mercado, água para consumo humano, produção escolar, relações sociais de gênero, associativismo, cooperativismo, comunicação democrática e comunitária. Tudo isso, em interface com a Educação Contextualizada, entendendo que sem ela o desenvolvimento rural sustentável torna-se inviável. Dessa forma, possibilitando uma atuação em que tem sido possível consolidar políticas públicas.

A mudança da visão de semiárido no Território incentivada pelo MOC possibilitou que a organização política, econômica, social e educacional do Território passasse a se estruturar na visão da Convivên- 
cia com o Semiárido, demandando do Poder Público políticas públicas e não mais aceitação de políticas assistenciais. Essa abertura e diálogo garantiram grandes conquistas, desde quando a Política Territorial passou a também ser fomentada na perspectiva do desenvolvimento local e as ações dos Movimentos Sociais e Sociedade Civil Organizada foram reconhecidas e potencializadas, num período em que historicamente o semiárido passa a ser visto como um lugar de gente e não de esvaziamento.

A diminuição considerável do analfabetismo, da extrema pobreza, construção de escolas do campo, diminuição da evasão escolar, do trabalho e da mortalidade infantil e do êxodo rural estão ligadas diretamente às ações do $\mathrm{MOC}$ em sua rede de parcerias pelo Território, bem como as mudanças ocasionadas pelos Programas Sociais a exemplo do Bolsa Família, a chegada do Mais Médicos garantiram mais qualidade de vida para as populações do campo. A garantia da educação do campo enquanto Lei em 16 municípios do Território assegura não só o reconhecimento da metodologia CAT, como a retira do status de projeto e eleva à política pública.

Portanto, as ações de incidência do MOC na educação do Território do Sisal contribuíram para a diminuição da extrema pobreza no Território do Sisal, possibilitando que mais de 30.000 crianças no território tivessem e tenham acesso à educação contextualizada, a partir de materiais didáticos, boletins, intercâmbios e formação continuada de mais de 500 professores/as, acompanhamento das organizações da Sociedade Civil para controle social, gestores municipais e escolares, incidência nos Conselhos Municipais de Educação, Segurança Alimentar e Conselho Estadual da Criança e Adolescente, com o olhar voltado para as crianças como objetivo final de todas as suas ações.

Enfim, muitos são os desafios que se apresentam para o Território do Sisal, que por mais que haja uma capacidade peculiar de organização social, possui ainda muita pobreza advinda do descaso histórico e que enfrenta nesses últimos tempos a ameaça de fechamento de escolas do campo. Há ainda muito a ser feito para erradicação da pobreza, desigualdades sociais, inclusive erradicação do trabalho infantil no Brasil e na região sisaleira do Sertão Baiano. Região a qual, 
como visto, tem perspectivas de melhoria a partir da ação do MOC e seus parceiros no Território do Sisal, tendo a educação contextualizada como ferramenta de empoderamento, organização e emancipação.

\section{REFERÊNCIAS}

ARROYO, M. G; CALDART, R. S; MOLINA, M. C. Por uma educação do campo. Petrópolis, RJ: Vozes, 2004.

ASA, Articulação no Semiárido Brasileiro. Declaração do Semiárido. 1999. Disponível em: <http://www.asabrasil.org.br/UserFiles/Filel DECLARACAO DO SEMIARIDO.pdf. $>$. Acesso em: 25 de setembro de 2017.

BAPTISTA, F. M. C. Baú de Leitura: Lendo Histórias, Construindo Cidadania. $2^{\circ}$ ed. João Pessoa-PB: 2006.

BRASIL, Resolução CNE/CEB n. ${ }^{0}$ 1, de 3 de abril de 2002 - Diretrizes Operacionais para a Educação Básica nas Escolas do Campo. Brasília, DF: 2002.

CALDART, R. S. (Org.). Educação do Campo: Identidade e Políticas Públicas. Brasília, DF: Articulação Nacional por uma Educação do Campo, 2002.

CALDART, R. S. Momento atual da educação no campo. 2004. Disponível em:

http://www.nead.org.br/index.php?acao=artigo\&id=27. Acesso em: 27 out. 2017.

CARNEIRO, V. M. O. Educação do Campo Contextualizada no Semiárido- O "Movimento de Organização Comunitária- MOC." 2011. MIMEO.

CARNEIRO, V. M. O. Educação do Campo: Construindo Saberes e Transformação Social no Território do Sisal. 2012, Dissertação 
(Mestrado). Pela Universidade do Estado da Bahia. Santo Antônio de Jesus-BA: UNEB, 2012.

DESTREMAU, B; SALAMA, P. O tamanho da pobreza: economia política da distribuição de renda. Rio de Janeiro: Garamond, 1999.

DUARTE, A. P. M. et. al. MOC: rumo aos 50 anos. Compartilhando experiências, construindo aprendizagens. Movimento de Organização Comunitária, EMGRAF, 2015.

KOLLING, E. J; NERY, I. J; MOLINA, M. C, (Orgs.). A Educação Básica e o Movimento Social do Campo. Brasília: UnB, 1999.

LIMA, E. S; SILVA, A. M. (Orgs.). Diálogos sobre Educação do Campo. 2. ed. Teresina- PI: EDUFPI, 2014.

MDA. Ministério do Desenvolvimento Agrário. Territórios Rurais. Brasília, n. 1, jan.-jun. 2008.

MOC - Movimento de Organização Comunitária. Territórios em Movimento- Relatório de Atividade. Feira de Santana: MOC, 2015. Disponível em: http://www.moc.org.br/relatorios. Acesso em: 10 de setembro de 2017.

PEREIRA, A. G. (Org.). A educação segundo o Semiárido. Ceará. Secretaria de Cultura do Estado. Fortaleza-CE: Premius, 2013.

REIS, E. S. Educação do Campo: escola, currículo e contexto. Juazeiro-BA: ADAC/UNEB-DCH-III/NEPEC-SAB, 2011.

ROSA, D. S; CAETANO, M. R. Da educação rural à educação do campo: uma trajetória: Seus desafios e suas perspectivas. Revista Científica da Faccat, v. 6, n. 1-2, jan/dez. 2008.

SILVA, M. B; GRIGOLO, T. M. Metodologia da pesquisa e elaboração de dissertação. 3. ed. Florianópolis: EDUFSC, 2002.

SILVA, M. do S. Org. Sementes de Educação Contextualizada: resultados e caminhos encontrados na pesquisa do Projeto CAT/MOC/ ICEP/UFCG. Feira de Santana- BA: Curviana, 2015. 
SILVA, M. S., CARVALHO, I. M. (Orgs.). Educação Contextualizada no Semiárido Baiano: a contribuição do CAT para as políticas de educação e a escola do campo. MOC- Feira de Santana- BA: Editora Curviana, 2015.

SOUZA, J. M. Educação: textos de intervenção. O Liberal: 2004.

STREETEN, P. P. Thinking about development. Cambridge (UK): Cambridge University Press, 1995.

WILKINSON, R.; PICKETT, K. The spirit level: why equality is better for everyone. London (UK): Penguin, 2010. 